\title{
High density plasma deposition of device quality silicon nitride. II. Effects of thickness on the electrical properties
}

\author{
M. C. Hugon, F. Delmotte, ${ }^{\text {a) }}$ and B. Agius \\ Laboratoire Charles Fabry de l'Institut d'Optique (URA D0014), 91403 Orsay, France \\ E. A. Irene \\ Department of Chemistry, University of North Carolina, Chapel Hill, North Carolina 27599-3290
}

(Received 28 October 1998; accepted 9 April 1999)

\begin{abstract}
Dielectric behavior of $\mathrm{SiN}_{x}$ films, fabricated by microwave electron cyclotron resonance discharge, has been studied as a function of film thickness on the basis of the current-voltage and the capacitance-voltage characteristics. In the thickness range $(20 \mathrm{~nm}<d<80 \mathrm{~nm})$, the resistivity and the critical field for $\operatorname{SiN}_{x}$ were found not to be sensitive to the film thickness $(d)$ and which was opposite to strong dependence of the dynamic dielectric constant $\epsilon_{d}$ on thickness. To explain the $\epsilon_{d}$ behavior as a function of $d$, a model based on trapped space charge effects is proposed. The dominant mode of electronic conduction, determined from $J-E^{1 / 2}$ curves and Arrhenius plots of leakage current, appears to be Poole-Frenkel emission only for thicker films $(d>20 \mathrm{~nm})$. Finally, the spatial profile of fixed charges reveals that $\mathrm{SiN}_{x} / \mathrm{Si}$ interface has a much greater concentration of defects than the bulk film. (C) 1999 American Vacuum Society. [S0734-211X(99)00704-0]
\end{abstract}

\section{INTRODUCTION}

$\mathrm{SiN}_{x}$ thin films have important applications in microelectronics, optoelectronics, optics, and hard surface coatings. Presently, in the ultralarge scale integration (ULSI) circuit applications, as device dimension shrink into the submicron range, a proportional decrease in the gate dielectric thickness is indispensable. ${ }^{1}$ For the development of InP based microelectronics, the formation of a high quality dielectric insulator is key to technology. As a consequence, low temperature deposition is required to prevent thermal decomposition of the InP surface. ${ }^{2-5}$ These different requirements have stimulated considerable research on the plasma deposition of dielectric thin films in particular the use of high density plasmas (HDPs). ${ }^{6}$

With film thicknesses below $20 \mathrm{~nm}$ now commonplace, control of the film physical and electrical properties becomes very critical. Only a few papers dealing with the electrical characteristics of $\mathrm{SiN}_{x} / \mathrm{Si}$ structures have been published, ${ }^{4,7}$ even though the behavior of $\mathrm{SiN}_{x}$ devices strongly depends on the film's electrical properties, especially when the film thickness is less than $20 \mathrm{~nm}$. For example, Poole-Frenkel emission is known to be the dominant conduction mechanism for silicon nitride thin films deposited at high temperatures $\left(800-1000{ }^{\circ} \mathrm{C}\right)$ by low pressure chemical vapor deposition $(\mathrm{LPCVD})^{8}$ or by radio frequency plasma enhanced CVD (PECVD). ${ }^{9,10}$ However, only a few papers ${ }^{11}$ have described the electrical properties of $\mathrm{SiN}_{x}$ films deposited by electron cyclotron resonance (ECR)-PECVD, and it is not particularly obvious whether the conduction mechanism will be the same when the thickness varies from nanometers to hundreds of nanometers. Therefore, understanding of the conduction mechanism for such thin films is necessary.

In this article, we report the study of the electrical properties of $\mathrm{SiN}_{x}$ films deposited using the distributed ECR

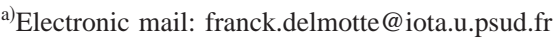

(DECR) plasma method at floating temperature, on silicon substrates, as a function of the film thickness in the 7-80 nm range. This DECR plasma process has proved to be one of the most suitable "soft" deposition techniques to obtain device quality insulator thin films with good electrical properties at very low substrate temperatures (below $150^{\circ} \mathrm{C}$ ). In view of the increasing interest in $\mathrm{SiN}_{x}$ interlayers in gate dielectric structures, the aim of this article is to study the electrical properties of $\mathrm{SiN}_{x}$ films by means of currentvoltage $(I-V)$, current-temperature $(I-T)$, and capacitance-voltage $(C-V)$ measurements. We focus essentially on the positive fixed charge distribution and on the determination of dominant conduction mechanisms.

\section{EXPERIMENT}

The DECR equipment used in this study was described previously. ${ }^{12,13}$ Briefly, it consists of a $400 \mathrm{~mm}$ diam chamber equipped with a loadlock; the base pressure in both chambers is below $5 \times 10^{-5} \mathrm{~Pa}$. The microwave power $(2.45$ $\mathrm{GHz}$ ) is coupled to the plasma through 14 antennas evenly distributed at the periphery of the chamber and permanent magnets $(875 \mathrm{G})$ are placed near each antenna outside the chamber.

$\mathrm{SiN}_{x}$ films were deposited on (100) n-type (5-6 $\times 10^{15} \mathrm{~cm}^{-3}$ ) silicon substrates. Before loading into the chamber, the substrates were subjected to conventional RCA cleaning. ${ }^{14}$ This cleaning procedure ended with a 1 min rinse in diluted HF, a $10 \mathrm{~min}$ rinse in de-ionized (DI) water and being blown dry with nitrogen.

The deposition process parameters were the same throughout this study: the pressure and microwave power were $0.3 \mathrm{~Pa}$ and $1500 \mathrm{~W}$, respectively, and the $\mathrm{N}_{2} / \mathrm{SiH}_{4}$ flow ratio was fixed to $19\left(19 \mathrm{sccm} \mathrm{N}_{2}\right.$ and $\left.1 \mathrm{sccm} \mathrm{SiH}_{4}\right)$. From our previous results, these process parameters allow us to optimize the physical and electrical properties of $\mathrm{SiN}_{x}$ thin 
THICKNESS $(\mathrm{nm})$

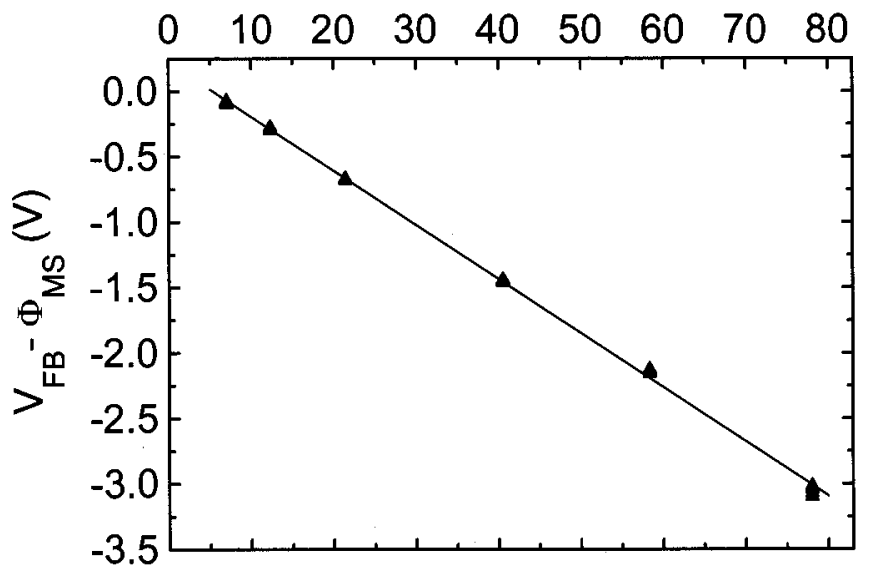

FIG. 1. $\Delta V_{\mathrm{FB}}-\Phi_{\mathrm{MS}}$ as a function of film thickness $\left(P=1500 \mathrm{~W}, \mathrm{~N}_{2} / \mathrm{SiH}_{4}\right.$ $=19, p=0.3 \mathrm{~Pa}$ ).

films. ${ }^{5,13,15}$ These films display a homogeneous composition over a large thickness range $(7-100 \mathrm{~nm})$. However, the film stoichiometry near the $\mathrm{SiN}_{x} / \mathrm{Si}$ interface $(\mathrm{N} / \mathrm{Si}=1.52$ $\pm 0.05)$ is higher than in the film bulk. From a previous spectroscopic ellipsometry study, an interface layer with a lower index than that in the bulk film is necessary for modeling the $\mathrm{SiN}_{x} / \mathrm{Si}$ structure. ${ }^{16}$

For the electrical measurements, Al dots of $0.152 \mathrm{~mm}^{2}$ were evaporated through a shadow mask. The metalinsulator-semiconductor (MIS) structures were then annealed for $30 \mathrm{~min}$ at $450{ }^{\circ} \mathrm{C}$ in forming gas $\left(\mathrm{Ar}+10 \% \mathrm{H}_{2}\right)$. The electrical properties were characterized with $(I-V)$ measurements carried out with a HP 4140B picoammeter at various temperatures within the range of $150-500 \mathrm{~K}$, the structure being biased in the accumulation regime. High frequency (1 MHz) $C-V$ characteristics, performed at room temperature with an impedance analyzer (HP 4192 A), were used to estimate the density of the fixed charges in the film.

\section{RESULTS AND DISCUSSION}

\section{A. Fixed charge distribution}

In our previous study of $\mathrm{SiN}_{x} / \mathrm{Si}$ structures, ${ }^{16}$ we showed evidence for the presence of an interface layer with a higher $\mathrm{N} / \mathrm{Si}$ ratio than the bulk film and having a lower refractive index than the bulk $\mathrm{SiN}_{x}$ film. In the present study our $C-V$ characteristics show a large flat band voltage shift $\left(\Delta V_{\mathrm{FB}}\right)$ toward negative values which is indicative of fixed positive charges in the $\mathrm{SiN}_{x}$ films. The $\Delta V_{\mathrm{FB}}$ values indicate about $10^{12} \mathrm{~cm}^{-2}$ positive charges assuming that the charges are at the interface of the $\mathrm{SiN}_{x} / \mathrm{Si}$ capacitor or in the bulk of the $\mathrm{SiN}_{x}$ layer. ${ }^{13,15}$ This high level of positive charges has been previously observed in similar films. ${ }^{9,10}$ Figure 1 displays $\Delta V_{\mathrm{FB}}-\Phi_{\mathrm{MS}}$ as a function of film thickness $(d)$ where $\Phi_{\mathrm{MS}}$ is the work function difference between the $\mathrm{Al}$ gate and the semiconductor. If $\Delta V_{\mathrm{FB}}$ is due to an uniform fixed charge distribution, we would expect that $\Delta V_{\mathrm{FB}}$ varies like $d^{2}$. Since Fig. 1 shows a linear relationship, we conclude that the fixed charges are not distributed uniformly in the film. If we
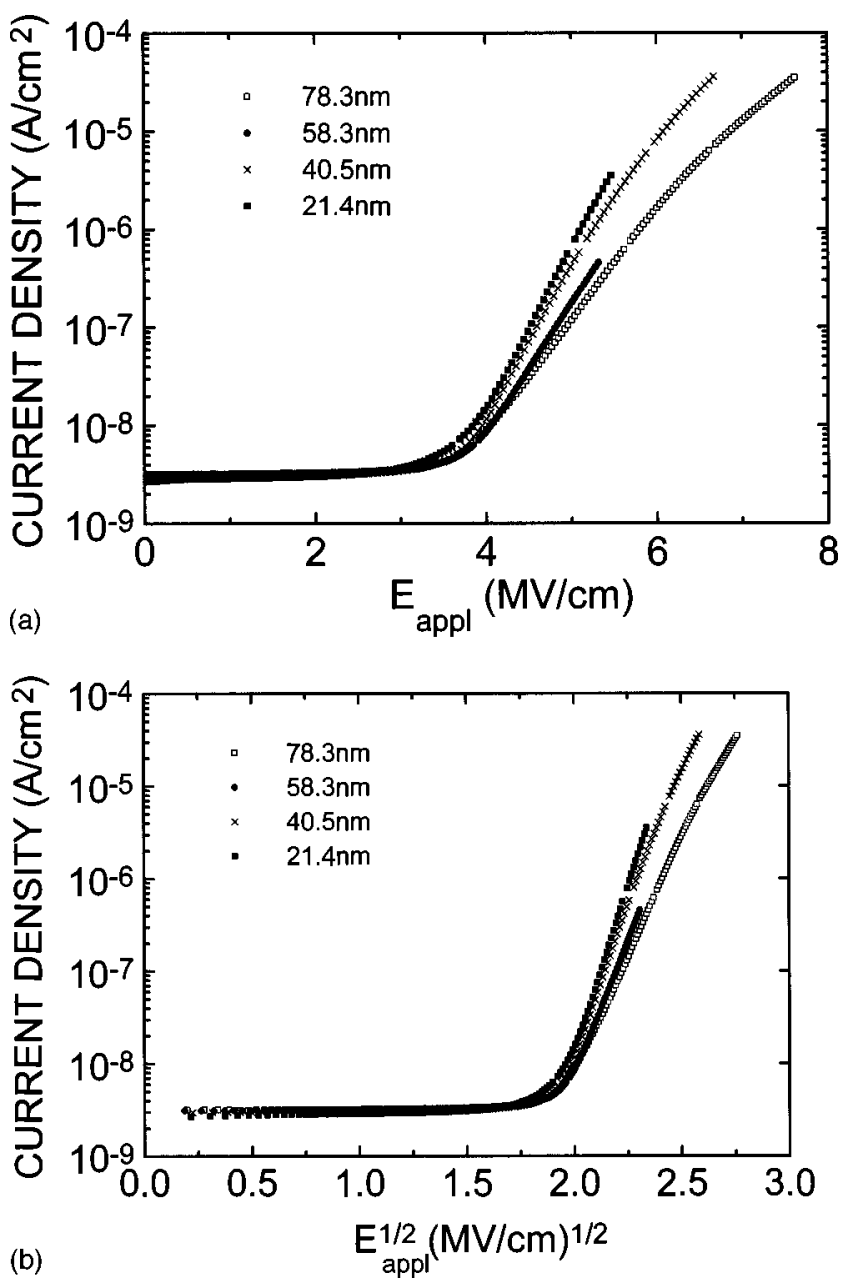

FIG. 2. Current density vs electric field $\left(J-E_{\text {appl }}\right)$ (a) and square root of the electric field $\left(J-E_{\text {appl }}^{1 / 2}\right)$ (b) for different film thicknesses [78.3, 58.3, 40.5, and $21.4 \mathrm{~nm}$ (electric field ramp $\left.\left.5 \times 10^{-3} \mathrm{MV} / \mathrm{cm} \mathrm{s}\right)\right](P=1500 \mathrm{~W}$, $\left.\mathrm{N}_{2} / \mathrm{SiH}_{4}=19, p=0.3 \mathrm{~Pa}\right)$.

assume that the fixed charges are mainly located at the $\mathrm{SiN}_{x} / \mathrm{Si}$ interface where the film is nitrogen rich, the charge distribution $\left[Q_{f}(x)\right]$ could be described by the following:

$$
\begin{aligned}
& Q_{f}(x)=\rho_{0} \text { for } 0<x<d_{1}, \\
& Q_{f}(x)=0 \text { for } x>d_{1},
\end{aligned}
$$

where $d_{1}$ is the characteristic length that describes the fixed charge location. Thus, $\Delta V_{\mathrm{FB}}$ varies linearly with $d^{2}$ only for $0<x<d_{1}$ [Eq. (1)] and $\Delta V_{\mathrm{FB}}$ should display a linear dependence with $d$ for $x>d_{1}$ [Eq. (2)]. This charge profile is in better agreement with the results in Fig. 1 and provides further evidence that the $\mathrm{SiN}_{x} / \mathrm{Si}$ interface and $\mathrm{SiN}_{x}$ bulk film are different.

\section{B. Thick films}

The current density versus applied electric field strength $\left(J-E_{\text {appl }}\right)$ characteristics for thick $\operatorname{SiN}_{x}$ films (78.3, 58.3, 40.5, and $21.4 \mathrm{~nm}$ ) are shown in Fig. 2(a), and these data were obtained using an electric field ramp rate $(r)$ of 5 $\times 10^{-3} \mathrm{MV} / \mathrm{cms}$. For low electric fields $(<4 \mathrm{MV} / \mathrm{cm})$, the 
TABLE I. Electrical properties $\left(\rho, E c\right.$, and $\left.\epsilon_{d}\right)$ as a function of film thickness $\left(P=1500 \mathrm{~W}, \mathrm{~N}_{2} / \mathrm{SiH}_{4}=19, p\right.$ $=0.3 \mathrm{~Pa})$.

\begin{tabular}{lcccccc}
\hline \hline $\begin{array}{c}\text { Electric field ramp } \\
(\mathrm{MV} / \mathrm{cm} \mathrm{s})\end{array}$ & $5 \times 10^{-3}$ & $5 \times 10^{-3}$ & $5 \times 10^{-3}$ & $5 \times 10^{-3}$ & $8 \times 10^{-3}$ & $1.4 \times 10^{-2}$ \\
\hline Thickness $(\mathrm{nm})$ & $78.3 \pm 0.5$ & $58.3 \pm 0.5$ & $40.5 \pm 0.5$ & $21.4 \pm 0.5$ & $12.3 \pm 1$ & $7 \pm 1$ \\
$\rho\left(10^{16} \Omega \mathrm{cm}\right)$ & $1.7 \pm 0.2$ & $1.3 \pm 0.2$ & $1 \pm 0.2$ & $0.7 \pm 0.1$ & $0.25 \pm 0.5$ & $0.12 \pm 0.05$ \\
$E c(\mathrm{MV} / \mathrm{cm})$ & $3.5 \pm 0.1$ & $3.5 \pm 0.1$ & $3.5 \pm 0.1$ & $3.2 \pm 0.1$ & $2.44 \pm 0.5$ & $1.45 \pm 0.5$ \\
$\epsilon_{d}$ & 7 & 5.4 & 3.7 & 3.2 & $\cdots$ & $\cdots$ \\
\hline \hline
\end{tabular}

different $J-E_{\text {appl }}$ characteristics are similar, and from this initial (low field) region of the $J-E_{\text {appl }}$ data, we determine the film resistivity $(\rho)$ from the slope of the $J-E_{\text {appl }}$ curve at low voltages as well as the critical field $(E c)$ which is defined as the field required for a $1 \mathrm{nA} \mathrm{cm}^{-2}$ increase of the current density through the Al gate. The values of $\rho$ and $E c$ for different thicknesses are reported in Table I. For films with thickness in the range of $20-78 \mathrm{~nm}$, only small variations of $\rho$ and $E c$ are observed and values of $0.7 \times 10^{16}-1.7$ $\times 10^{16} \Omega \mathrm{cm}$ and 3.2-3.5 MV/cm, respectively, are obtained for $\rho$ and $E c$, which are two electrical properties that describe the bulk behavior of $\operatorname{SiN}_{x}$ films. As was the case for the film composition, ${ }^{5} \rho$ and $E c$ are independent of the film thickness in the film thickness range of $20-78 \mathrm{~nm}$.

For high electric fields $(>4 \mathrm{MV} / \mathrm{cm})$, the shape of the $J-E_{\text {appl }}$ data is different, as is shown in Figs. 2(a) and 2(b), and is directly related to the conduction mechanism in $\operatorname{SiN}_{x}$ films. Figure 2(b) shows that $\ln J$ is linear with $E_{\text {appl }}^{1 / 2}$ which suggests that the carrier transport process in $\mathrm{SiN}_{x}$ films is via Poole-Frenkel emission, as is commonly observed, ${ }^{8-10}$ and the current-voltage characteristics can be expressed as

$$
J=J_{0} \exp \left(\frac{-q}{k T}\left[\phi-\beta \sqrt{E_{\text {appl }}}\right),\right.
$$

where $J, \phi$, and $J_{0}$ are, respectively, the current density, the Poole-Frenkel barrier height, and a constant that depends on trap density. $E_{\text {appl }}$ is equal to $V / d$ where $V$ and $d$ are the applied voltage and the dielectric film thickness, respectively. $\beta$ is given by

$$
\beta=\left(\frac{q}{\pi \epsilon_{0} \epsilon_{d}}\right)^{1 / 2}
$$

where $\epsilon_{0}$ and $\epsilon_{d}$ are, respectively, the dielectric constant of free space and the dynamic dielectric constant of $\mathrm{SiN}_{x}$ films. Figure 2(b) shows that for all the film thickness studies there is a linear relationship between $\ln J$ and $E_{\text {appl }}^{1 / 2}$. The dynamic dielectric constant is determined directly from the slope of the characteristic $\ln J$ vs $E_{\text {appl }}^{1 / 2}$ and Eqs. (3) and (4). The results are reported in Table I. These results show that $\epsilon_{d}$ is a strong function of film thickness while $\rho, E c$, and the atomic ratio $\mathrm{N} / \mathrm{Si}$ remain constant in this thickness range (20-78 $\mathrm{nm})$. This suggests that the conduction mechanism changes with the thickness. For the determination of $\epsilon_{d}$, it has been incorrectly assumed that the electric field is constant in $\operatorname{SiN}_{x}$ films and equal to $E_{\text {appl }}$. In fact, it is well known that injected carriers (electrons in our case) from $\mathrm{Si}$ are trapped in the nitride film and a space charge is built up. ${ }^{17}$ Therefore, the electric field is different at the $\mathrm{SiN}_{x} / \mathrm{Si}$ interface and in the bulk nitride film. The distribution of occupied electronic traps, $N_{T}$, is the result of the trapping and emission rates for electrons. Andrews et al. ${ }^{18}$ assumed that $N_{T}$ is an exponentially decreasing function of distance from the injecting interface and given as

$$
N_{T}=N_{0} \exp \left(-\frac{x}{x_{0}}\right)
$$

where $N_{0}$ is the trap density and $x_{0}$ is the characteristic length that describes electronic occupation traps. The electric field distribution $E(x)$ is deduced by integration of the Poisson equation:

$$
E=E_{0}+E_{T}\left[1-\exp \left(-\frac{x}{x_{0}}\right)\right], \quad \text { where } E_{T}=\frac{q N_{0} x_{0}}{\epsilon_{0} \epsilon_{S}},
$$

where $E_{0}$ represents the electric field without charge in $\mathrm{SiN}_{x}$ film, and $\epsilon_{S}$ is the static dielectric constant of the nitride film. Integrating the Poisson equation a second time yields the total voltage through the structure:

$V=\int_{0}^{d} E(x) d x=\left(E_{0}+E_{T}\right) d+E_{T} x_{0}\left[\exp \left(-\frac{d}{x_{0}}\right)-1\right]$.

From Eq. (7), the applied field can then be expressed as

$$
E_{\text {appl }}=\frac{V}{d}=\left(E_{0}+E_{T}\right)+\frac{E_{T} x_{0}}{d}\left[\exp \left(-\frac{d}{x_{0}}\right)-1\right] .
$$

Close to the $\mathrm{SiN}_{x}$ film/Si substrate interface, the traps are filled and a high negative space charge is present. Further into the dielectric, a point is reached where the traps are emptied $\left(\mathrm{N}_{T} \approx 0\right)$ due to field assisted emission [the PooleFrenkel (PF) mechanism]. This occurs at a field $E_{\mathrm{PF}}$ equals to

$$
E_{\mathrm{PF}}=E_{0}+E_{T}=E_{\mathrm{appl}}-\frac{E_{T} x_{0}}{d}\left[\exp \left(-\frac{d}{x_{0}}\right)-1\right] .
$$

If we assume that $d \gg x_{0}, E_{\mathrm{PF}}$ can be written as

$E_{\mathrm{PF}}=E_{\mathrm{appl}}+\frac{E_{T} x_{0}}{d}$.

Finally Eq. (3) should be written as

$J=J_{0} \exp \left(\frac{-q}{k T}\left[\phi-\beta_{\text {eff }} \sqrt{E_{\mathrm{PF}}}\right]\right)$.

$\beta_{\text {eff }}$ is given by an equation similar to Eq. (4): 


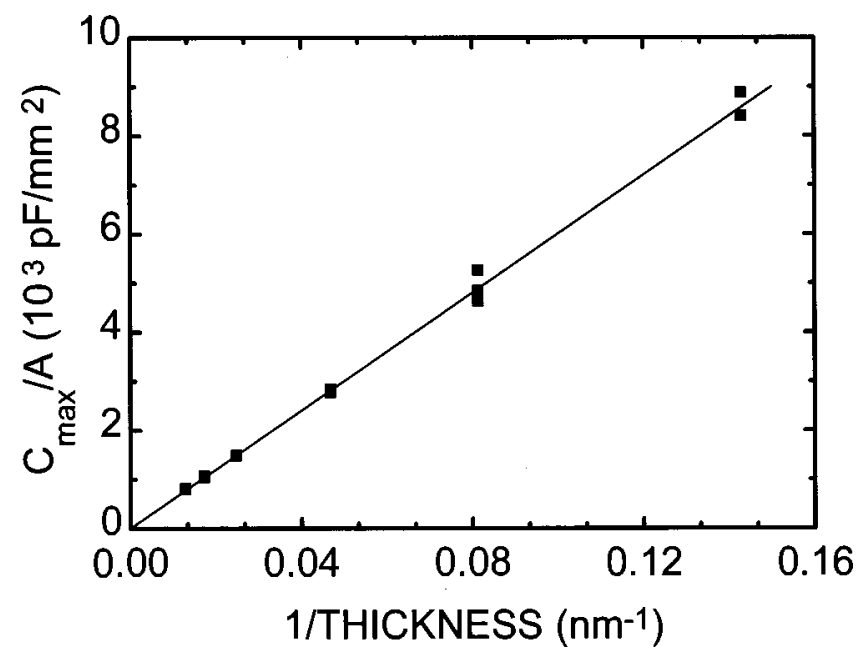

FIG. 3. $C_{\max } / A$ ratio as a function of $1 / d\left(P=1500 \mathrm{~W}, \mathrm{~N}_{2} / \mathrm{SiH}_{4}=19, p\right.$ $=0.3 \mathrm{~Pa}$ ).

$$
\beta_{\mathrm{eff}}=\left(\frac{q}{\pi \epsilon_{0}\left(\epsilon_{d}\right)_{\mathrm{eff}}}\right)^{1 / 2},
$$

where $\left(\epsilon_{d}\right)_{\text {eff }}$ is the effective dynamic dielectric constant of the film. From Eq. (10), $E_{\mathrm{PF}}$ decreases with increasing thickness. Therefore, for a given $E_{\text {appl }}$, the current density is lower for thick films. This result is confirmed by the $J-E_{\text {appl }}$ and $J-E_{\text {appl }}^{1 / 2}$ characteristics in Figs. 2(a) and 2(b), respectively. From Eq. (11), $\ln J$ is proportional to $E_{\mathrm{PF}}^{1 / 2}$. Since we observe a linear relationship between $\ln J$ and $E_{\mathrm{appl}}^{1 / 2}$, we deduce that $E_{\mathrm{PF}}$ is proportional to $E_{\text {appl }}\left(E_{\mathrm{PF}}=\alpha E_{\mathrm{appl}}, \alpha\right.$ being a constant that decreases with increasing $d$ ). Using Eqs. (3) and (11), we find that the apparent $\beta$ depends on nitride thickness:

$$
\frac{d \ln J}{d\left(E_{\mathrm{appl}}^{1 / 2}\right)}=\frac{q \beta}{k T}=\frac{q \beta_{\mathrm{eff}}}{k T} \alpha^{1 / 2} .
$$

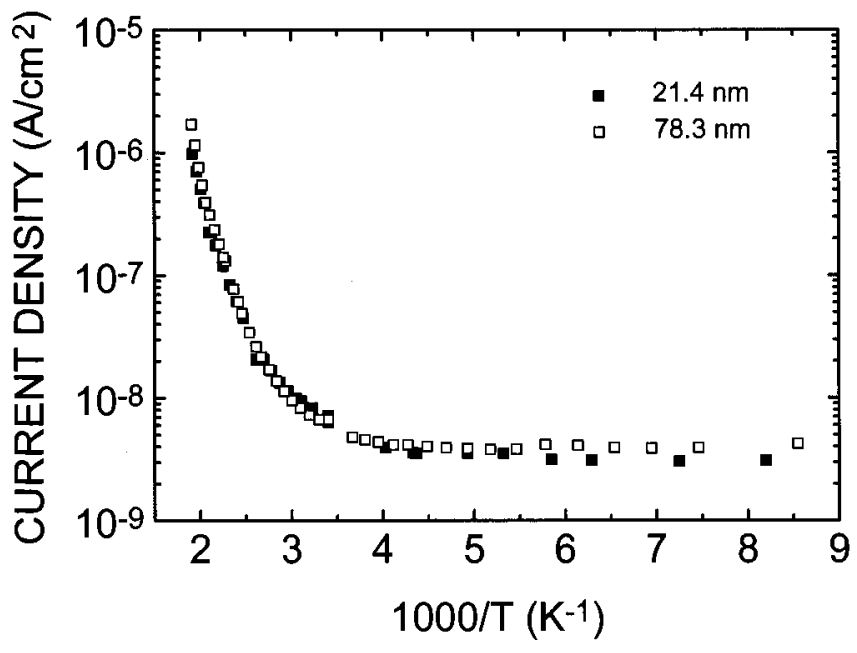

FIG. 4. Temperature dependence of the current density for two film thicknesses $(78.3$ and $21.4 \mathrm{~nm}) . \log J$ is represented vs $1 / T(P=1500 \mathrm{~W}$, $\left.\mathrm{N}_{2} / \mathrm{SiH}_{4}=19, p=0.3 \mathrm{~Pa}\right)$.
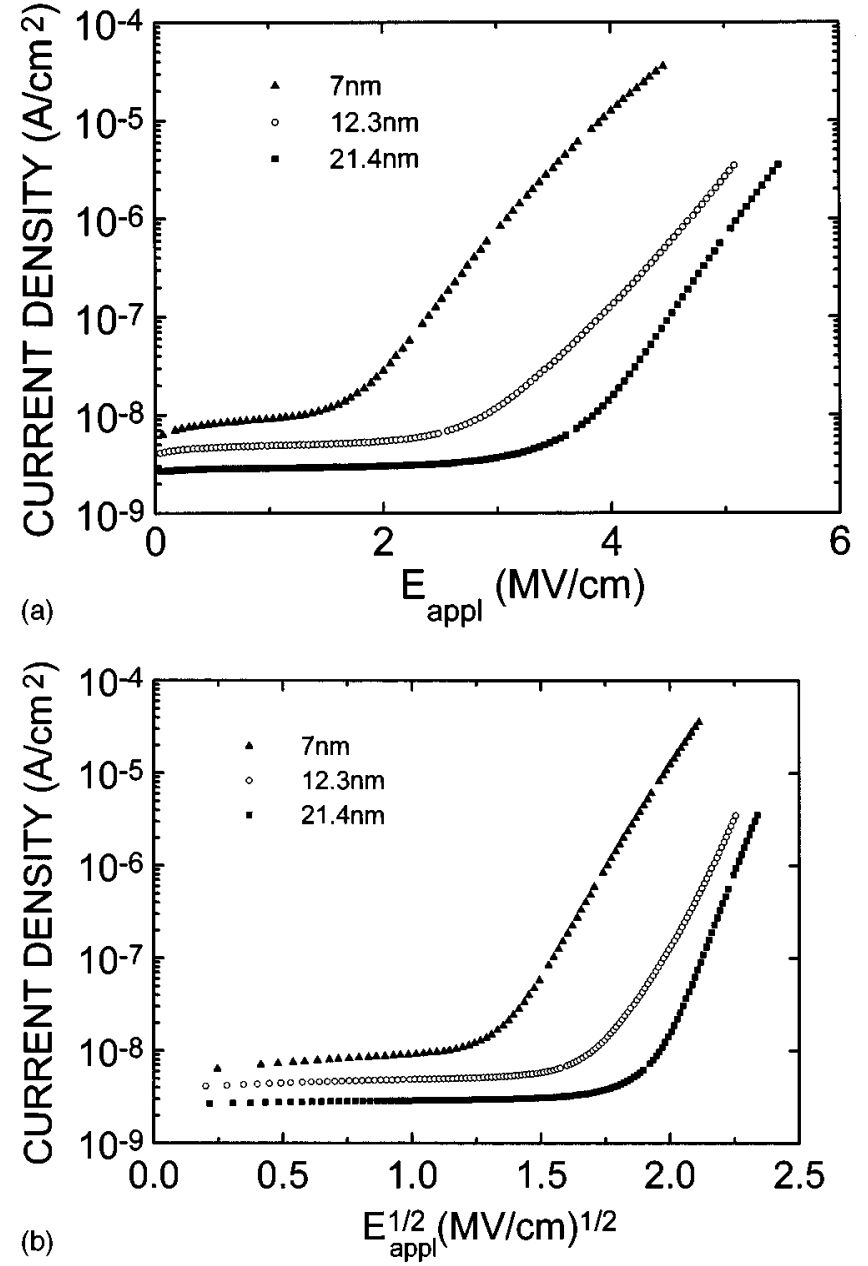

FIG. 5. Current density vs electric field $\left(J-E_{\text {appl }}\right)$ (a) and square root of the electric field $\left(J-E_{\text {appl }}^{1 / 2}\right)$ (b) for different film thicknesses $[21.4,12.3$, and 7 $\mathrm{nm}$ (for the electric field ramp; see Table I)] $\left(P=1500 \mathrm{~W}, \mathrm{~N}_{2} / \mathrm{SiH}_{4}=19\right.$, $p=0.3 \mathrm{~Pa})$.

Figure 3 shows a linear relationship between the $C_{\max } / A$ ratio and $1 / d$ where $C_{\max }$ and $A$ are, respectively, the capacitance in the accumulation regime and the Al dot area. Thus we can assume that the static dielectric constant $\epsilon_{S}$ does not depend on film thickness. Furthermore, we can assume that $\beta_{\text {eff }}$ is also independent of thickness $(20-78 \mathrm{~nm})$, since we observe no significant changes in $\rho, E c$, and $\epsilon_{S}$. Using Eq. (13), it is found that $\beta$ decreases with increasing $d$ and therefore the apparent $\epsilon_{d}$ increases with $d$. Table I confirms this conclusion for film thicknesses in the range of $20-78 \mathrm{~nm}$.

The value of the dynamic dielectric constant is quite high, especially for large film thicknesses $\left(\epsilon_{d}=7\right.$ for $\left.78.3 \mathrm{~nm}\right)$. Therefore, to confirm the Poole-Frenkel mechanism, it is necessary to examine the Arrhenius plots of leakage current for a constant electric field. Since the purpose of this article is not to find the charge distribution in $\mathrm{SiN}_{x}$ films, the same current density, measured at room temperature, was chosen. Figure 4 displays Arrhenius plots of leakage current for two different film thicknesses (78.3 and $21.4 \mathrm{~nm}$ ). At high temperature, the currents yield straight lines which strongly suggests that the electronic conduction corresponds to the Poole-Frenkel emission mechanism. 


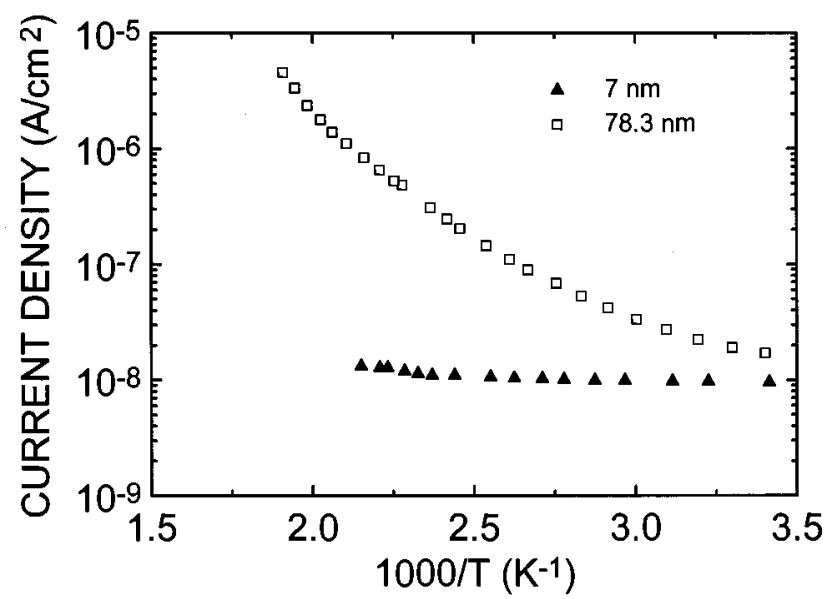

FIG. 6. Temperature dependence of the current density for two film thicknesses $(7$ and $21.4 \mathrm{~nm}) . \log J$ is represented vs $1 / T\left(P=1500 \mathrm{~W}, \mathrm{~N}_{2} / \mathrm{SiH}_{4}\right.$ $=19, p=0.3 \mathrm{~Pa})$.

From the dependence of $\ln J$ vs $1 / T$ in Fig. 4, the PooleFrenkel barrier height $\Phi$ is found to be $1.2 \pm 0.2 \mathrm{eV}$. In many silicon nitride films, the trap level $\Phi$ is in the range of 1-1.5 $\mathrm{eV} .{ }^{19}$ Since evaluation of $\Phi$ by Poole-Frenkel emission has an error of $\pm 0.2 \mathrm{eV}$, it is difficult to compare the conductivity of different silicon nitride films just by comparing the values of $\Phi$.

\section{Thin films}

Figure 5(a) and Table I show that, for thin films $(<21$ $\mathrm{nm})$, there is a degradation of electrical properties. Contrary to Fig. 2(a), Fig. 5 shows that in the low field region the film characteristics are different, but this difference is essentialy due to the electric field ramp rate $(r)$ which is not the same (see Table I). In the low field region, the current strongly depends on the displacement current $[I=C(d V / d t)]$ which is correlated to $r$ and depends slightly on the leakage current. As can be seen in Table I, the resistivity and critical field decrease with film thickness. This evolution could be correlated to the $\mathrm{SiN}_{x} / \mathrm{Si}$ interface which plays a more important role for thin films. However, we observe a linear relationship between $\ln J$ and $E_{\text {appl }}^{1 / 2}$ which could mean that the current density is governed by Poole-Frenkel emission. The value of the dynamic dielectric constant determined from the slope of the characteristic $\ln J$ vs $E_{\text {appl }}^{1 / 2}$ is too high $\left(\epsilon_{d}=8.4\right.$ for a thickness of $7 \mathrm{~nm}$ ) to attribute the conduction mechanism to Poole-Frenkel emission. The current is not or not only limited by the bulk conduction through the $\mathrm{SiN}_{x}$ film. An Arrhenius plot (Fig. 6) confirms this conclusion, and, contrary to Fig. 4, we observe a slight change of the current density as a function of the measurement temperature for thin films. Although the behavior is very similar to the Fowler-Nordheim emission process, the film is too thick (7 $\mathrm{nm})$ to consider this conduction mechanism. The $\mathrm{SiN}_{x} / \mathrm{Si}$ interface, which is more nitrogen rich and where the fixed charges are mainly located, now has more influence than the $\mathrm{SiN}_{x}$ bulk film.

\section{CONCLUSION}

In this article, a DECR plasma source has been used to deposit $\mathrm{SiN}_{x}$ films, at floating temperature, with thicknesses in the range of 7-80 nm. For films thicker than $20 \mathrm{~nm}$ the influence of film thickness is minimal on the resistivity $\left(0.7-1.7 \times 10^{16} \Omega \mathrm{cm}\right)$ and on the critical field (3.2-3.5 MV/ $\mathrm{cm})$. For these films, the dominant conduction mechanism is Poole-Frenkel emission. The trap level, as determined from the temperature dependence of current density, is equal to $1.2 \pm 0.2 \mathrm{eV}$. The assumption of a constant electric field throughout the structure is responsible for an apparent $\epsilon_{d}$ variation. For thinner films $(<20 \mathrm{~nm})$, the electrical properties become degraded, particularly the critical field ( $E c$ $=1.45 \mathrm{MV} / \mathrm{cm}$ for a $7 \mathrm{~nm}$ thick film). The conduction mechanism is not only determined by the bulk conduction; the $\mathrm{SiN}_{x} / \mathrm{Si}$ interface also plays an important role. This interface presents properties which differ from those for the $\mathrm{SiN}_{x}$ bulk film. We found, from $C-V$ characterization, that the fixed charges are mainly located at the $\mathrm{SiN}_{x} / \mathrm{Si}$ interface.

In conclusion, the DECR process appears to be a promising technique by which to prepare gate dielectric films in a wide range of thicknesses.

\section{ACKNOWLEDGMENTS}

This work was supported by the Centre National de la Recherche Scientifique (GDR86) and France Telecom. One of the authors (E.A.I.) gratefully acknowledges the support of the National Science Foundation (NSF) Division of Materials Research.

\footnotetext{
${ }^{1}$ A. Izumi and H. Matsumura, Appl. Phys. Lett. 71, 1371 (1997).

${ }^{2}$ R. W. M. Kwok, W. M. Lau, D. Landheer, and S. Ingrey, J. Vac. Sci. Technol. A 11, 990 (1993).

${ }^{3}$ D. Landheer, G. H. Yousefi, J. B. Webb, R. W. M. Kwok, and W. M. Lau, J. Appl. Phys. 75, 3516 (1994).

${ }^{4}$ S. Garcia, I. Martil, G. Gonzalez Diaz, E. Castan, S. Duesñas, and F. Fernandez, J. Appl. Phys. 83, 600 (1998).

${ }^{5}$ M. C. Hugon, F. Delmotte, B. Agius, and J. L. Courant, J. Vac. Sci. Technol. A 15, 3143 (1997).

${ }^{6}$ M. A. Lieberman and R. A. Gottscho, Phys. Thin Films 18, 1 (1994)

${ }^{7}$ Y. C. Park, W. B. Jackson, N. M. Johnson, and S. B. Hagstrom, J. Appl. Phys. 68, 5212 (1990).

${ }^{8}$ S. M. Sze, J. Appl. Phys. 38, 2951 (1967).

${ }^{9}$ S. V. Hattangady, G. G. Fountain, R. A. Rudder, and R. J. Markunas, J. Vac. Sci. Technol. A 7, 570 (1989).

${ }^{10}$ S. W. Hsieh, C. Y. Chang, Y. S. Lee, C. W. Lin, and S. C. Hsu, J. Appl. Phys. 76, 3645 (1994).

${ }^{11}$ Y. C. Jeon, H. Y. Lee, and S. K. Joo, J. Appl. Phys. 75, 979 (1994).

${ }^{12}$ F. Plais, B. Agius, F. Abel, J. Siejka, M. Puech, G. Ravel, P. Alnot, and N. Proust, J. Electrochem. Soc. 139, 1489 (1992)

${ }^{13}$ S. Sitbon, M. C. Hugon, B. Agius, F. Abel, J. L. Courant, and M. Puech, J. Vac. Sci. Technol. A 13, 2900 (1995).

${ }^{14}$ W. Kern and D. A. Puotinen, RCA Rev. 6, 187 (1970).

${ }^{15}$ F. Delmotte, M. C. Hugon, B. Agius, and J. L. Courant, J. Vac. Sci. Technol. B 15, 1919 (1997).

${ }^{16}$ F. Delmotte, M. C. Hugon, B. Agius, and E. A. Irene, J. Vac. Technol. B (to be published).

${ }^{17}$ P. C. Arnett and D. J. DiMaria, J. Appl. Phys. 27, 34 (1975)

${ }^{18}$ J. M. Andrews, B. G. Jackson, and W. J. Polito, J. Appl. Phys. 51, 495 (1980).

${ }^{19}$ K. Watanabe and S. Wakayama, J. Appl. Phys. 53, 568 (1982).
} 